Yerbilimleri, 2020, 41 (1), 86-99, DOI:10.17824/yerbilimleri.597652

Hacettepe Üniversitesi Yerbilimleri Uygulama ve Araştırma Merkezi Bülteni

Bulletin of the Earth Sciences Application and Research Centre of Hacettepe University

\title{
Kayaç Dayanımı Değerlerine Göre Kazı Yönteminin Belirlenmesi
}

Determination of Excavation Method According to Rock Strength Values

\section{ABDURRAHMAN TOSUN ${ }^{1}$}

${ }^{1}$ Dokuz Eylül Üniversitesi, Mühendislik Fakültesi, Maden Mühendisliği Bölümü ve Bergama Meslek Yüksekokulu, Buca/Bergama/İzmir

$$
\begin{aligned}
& \text { Geliş (received): } 28 \text { Temmuz (July) } 2019 \\
& \text { Kabul (accepted) : } 25 \text { Nisan (April) } 2020
\end{aligned}
$$

Öz

Açık ocak madenciliğinde kazı işlemleri, genellikle direkt kazı ve gevşetme sonrası kazı olmak üzere iki şekilde yapılmaktadır. Kayaç dayanımı düşük olan sahalarda direkt olarak kazı yapılırken, tersi durumda ise delme-patlatma işlemiyle gevşetmeden sonra kazı operasyonları gerçekleştirilmektedir. Hangi kayaç dayanımı değerinden sonra gevşetme işleminin yapılması gerektiği üretimin ekonomik olarak yapılması açısından son derece önemlidir. Bu araştırmada açık işletme olarak çalışan bir kömür ocağında üç farklı kayaç dayanımı değerine sahip ve herhangi bir süreksizlik özelliği içermeyen bölgelerde çekme kepçeli yerkazar ile öncelikle direkt olarak kazı deneyleri yapılmıştır. Sonrasında ise aynı çalışma alanlarında delmepatlatma ile gevşetme yapıldıktan sonra yine aynı çekme kepçeli yerkazar ile kazı işlemi gerçekleştirilmiştir. Her iki durumda da birim kazı maliyetleri hesaplanarak karşıllaştırma yapılmış ve tek eksenli basınç dayanımı 9,80 MPa ve daha yüksek olan sahalarda gevşetme işleminden sonra kazı yapılmasının daha ekonomik olduğu görülmüştür.

Anahtar Kelimeler: Çekme kepçeli yerkazar, kazı, kayaç dayanımı.

https://doi.org/10.17824/yerbilimleri.597652

Abdurrahman TOSUN abdurrahman.tosun@deu.edu.tr

Dokuz Eylül Üniversitesi, Mühendislik Fak.,Maden Mühendisliği Bölümü ve Bergama Meslek Yüksekokulu, Buca/Bergama/Izmir, ORCID 0000-0001-9866-7847 


\section{Abstract}

In open pit mining, excavations are generally carried out in two ways: direct excavation and excavation after loosening. Direct excavation is performed in areas with low rock strength, and in the opposite case, excavation operations are carried out after loosening by drillingblasting. Which rock strength value should be performed for the loosening process is extremely important in terms of economic production. In this research, firstly, direct excavation experiments were performed with a dragline in an open pit coal mine that has work areas that have materials with three different rock strength values and without any discontinuity characterized. Then, in the same work areas, after drilling-blasting and loosening, the same dragline was used in the excavation. In both cases, unit excavation costs were calculated and compared, and it was found to be more economical to excavate after loosening at sites with uniaxial compressive strength of $9.80 \mathrm{MPa}$ and higher.

Key Words: Dragline, excavation, rock strength.

\section{GíRiş}

Açık ocak madenciliğinde üretim sırasında, cevhere ulaşmak için önce dekapaj, sonra da cevher kazısı yapılmaktadır. Kazı işlemleri genellikle direkt kazı ve gevşetme sonrası kazı olmak üzere iki şekilde yapılmaktadır. Mekanik özellikleri düşük ve yapısal özellikleri zayıf olan kayaç kazılarında direkt olarak kazı operasyonları yapılmaktadır. Gevşetme sonrası kazı ise direkt olarak kazılması mümkün olmayan sert kayaçlarda önce patlatma ile kayaç gevşetilmekte sonra da kazı yapılmaktadır. Kazılabilirliği etkileyen parametrelere göre kazı yöntemi seçimi çok sayıda araştırmacı tarafından incelenmiştir. Franklin vd. (1971) kayacın süreksizlik aralığı, nokta yük dayanımı ve tek eksenli basınç dayanımı değerlerini kullanarak bir grafik oluşturmuş ve grafiğe göre kayacın kazılabilirlik yöntemini belirlemeye çalışmıştır. Daha sonra Pettifer ve Fookes 1994'de Franklin'in belirlediği grafiği detaylandırarak güncellemiştir. Weaver (1975) sismik hız, kayacın tek eksenli basınç dayanımı, süreksizlik aralığı, süreksizlik devamlılığı, süreksizlik açıklığı ve doğrultu ve eğim yönelimi parametrelerinin her birine kendi arasında puanlar vererek kazı yöntemini tespit etmeye çalışmıştır. Kirsten (1982) kayacın tek eksenli basınç dayanımı, kaya kalite göstergesi (RQD), süreksizlik takımı sayısı, zemin yapısı, süreksizliklerin pürüzlülüğü ve süreksizliklerin alterasyonu parametrelerine göre sökücü dozer tiplerinin kullanılması gerektiğini 
vurgulamıştır. Abdüllatif ve Cruden (1983) yeraltı yapılarında tahkimat sistemlerinin boyutlandırmasında kullanılan RMR (Bieniawski, 1973) kaya kütle sınıflandırma sistemini kullanarak kayaçların kazılabilirlik yöntemlerini belirlemiştir. Yine konu ile ilgili olarak Müftüoğlu ve Scoble (1985) kayacın tek eksenli basınç dayanımı, nokta yük dayanımı, süreksizlik aralığı, katmanlaşma kalınlığı ve ayrışma derecesi parametreleriyle bir puanlama sistemi oluşturmuş ve puan durumuna göre kazı yöntemini tespit etmiştir. Singh vd. (1986) kayaç içindeki sismik hız, kayacın çekme dayanımı, süreksizlik aralığı, ayrışma derecesi ve kayacın aşındırıcılığı parametreleriyle kazılması istenen kayaç yapısına puanlar vermiş ve yine bu puanlara göre kazı yöntemi önermiştir. Karpuz (1990) kayacın tek eksenli basınç dayanımı, nokta yük dayanımı, süreksizlik aralığı, ayrışma derecesi ve kayaç içindeki sismik hız parametreleriyle bir puanlama sistemi oluşturmuş ve puan durumuna göre kazı yöntemi ve kazıcı tiplerini tespit etmiştir. Göktan ve Eskikaya (1991) süreksizlik tabakalanması, eklem takımları ve kayacın tek eksenli basınç dayanımı değerleriyle kaya kütlesi sökülebilirlik indeksi belirlemişler ve bu indekse göre de dozerin net kazı hızını tespit etmişlerdir. Kazısı yapılacak olan bölgenin kazılabilirlik yönteminin belirlenebilmesi için kayaç dayanımının önemli bir parametre olarak ortaya çıktığı yukarıdaki çalışmalardan anlaşılmaktadır. Bu kapsamda hangi kayaç dayanımı değerinden sonra delme-patlatma işleminin uygulanacağı önemlidir. Dolayısıyla kayaç dayanımı değerinin, kazı ve delme-patlatma maliyetlerine göre optimizasyonunun belirlenmesi gerekmektedir. Aksi takdirde üretim sırasında gereksiz maliyet artışları olacaktır.

Bu çalışmada açık işletme olarak çalışan bir kömür ocağında üç farklı kayaç dayanımı değerine sahip ve herhangi bir süreksizlik özelliği içermeyen bölgelerde çekme kepçeli yerkazar ile öncelikle direkt olarak kazı deneyleri yapıımıştır. Sonrasında ise aynı çalışma alanlarında delme-patlatma ile gevşetme yapıldıktan sonra yine aynı çekme kepçeli yerkazar ile kazı işlemi gerçekleştirilmiştir. Her iki durumda da kazı ve delme-patlatma maliyetleri hesaplanarak karşılaştırma yapıımıştır. Böylece hangi kayaç dayanımından sonra gevşetmekazı operasyonunun ekonomik olduğu tespit edilmiştir. Aşağıda öncelikle çalışma sahası ve deneyler sırasında kullanılan çekme kepçeli yerkazar hakkında bilgiler verilmiş sonrasında ise laboratuvar ve arazi çalışmaları anlatılmıştır. 


\section{ÇALIŞMA SAHASI VE KULLANILAN ÇEKME KEPÇELI YERKAZARIN ÖZELLIKLERI}

Araştırma, Muğla'nın Yatağan ilçesinde bulunan TKI kömür işletmesine ait Eskihisar olarak adlandırılan kömür ocağında gerçekleştirilmiştir. Çalışma sahasına ait görünüm Şekil 1'de verilmektedir. Deneyler, söz konusu ocağın üç farklı bölgesinde gerçekleştirilmiştir.

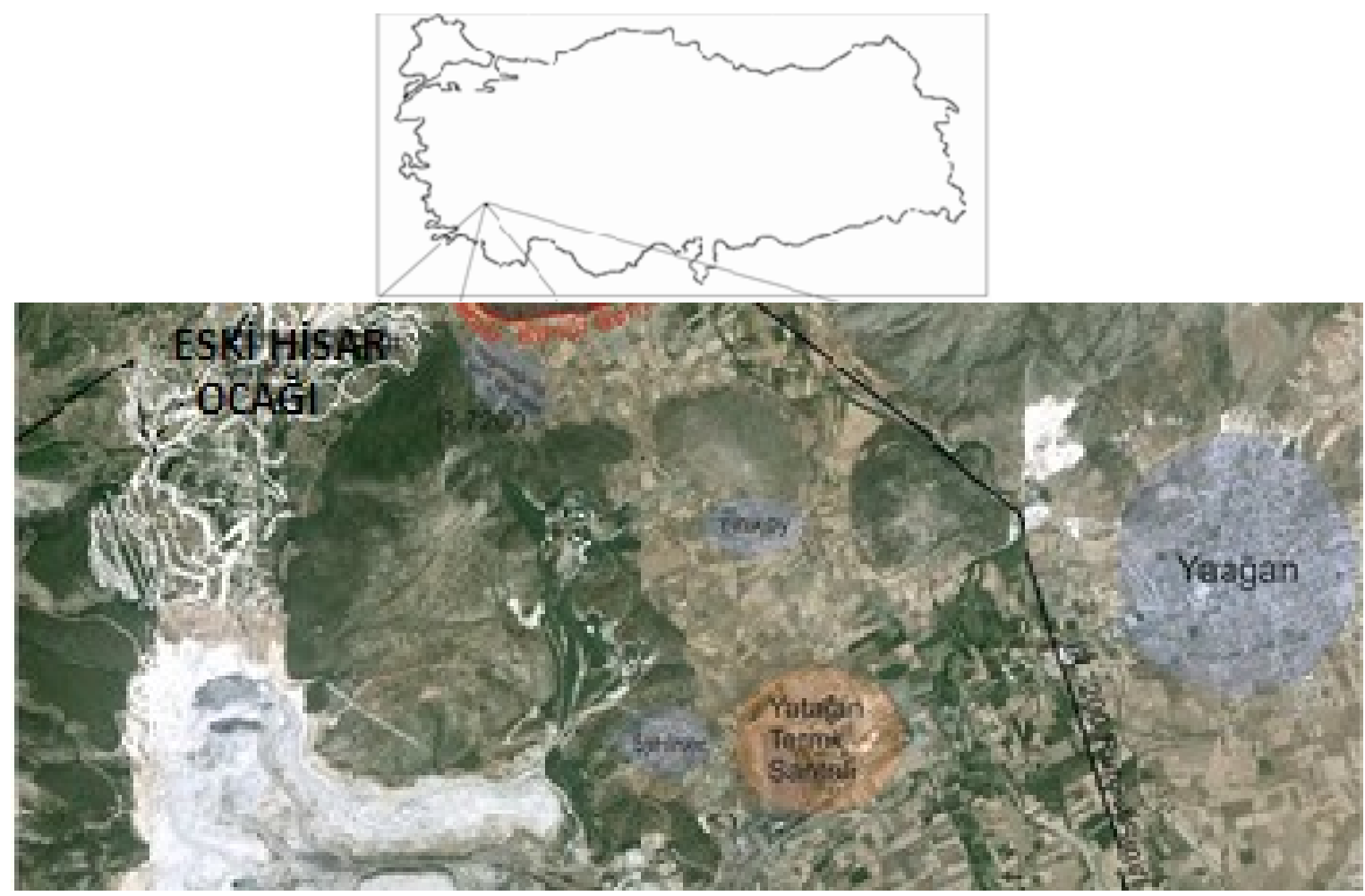

Şekil 1. Çalışma sahasının görünümü.

Figure 1. View of the study site.

Bu ocakta kömür ve onun üstündeki dekapaj kazısı çekme kepçeli yerkazar ve ekskavatörler ile gerçekleştirilmektedir. Deneyler sırasında Marion 8050 tipi çekme kepçeli yerkazar kullanılmıştır. Söz konusu çekme kepçeli yerkazar 3500 ton ağırığında olup $50 \mathrm{~m}^{3}$ kepçe kapasitesine sahiptir. Şekil 2'de çekme kepçeli yerkazarın görüntüsü ve Çizelge 1' de de çekme kepçeli yerkazara ait teknik veriler verilmiştir. 


\section{LABORATUVAR ÇALIŞMALARI}

Her üç çalışma sahasından numuneler alınmış ve kaya mekaniği laboratuvarında numunelere ait birim hacim ağırlığı ve tek eksenli basınç değerleri belirlenmiştir. Sonuçlara ait değerler Çizelge 2'de sunulmuştur. Çizelge 2'de ayrıca yapılan deney sayıları da verilmiştir.

Çizelge 1. Çalışmada kullanılan çekme kepçeli yerkazarın teknik özellikleri.

Table 1. Technical characteristics of the dragline used in the study.

\begin{tabular}{|c|c|c|c|c|}
\hline \multicolumn{5}{|c|}{ Marion 8050 Teknik Özellikleri } \\
\hline Üst Gövde & & Elektrik motol & & \\
\hline Kepçe kapasitesi & $50 \mathrm{~m}^{3}$ & DC motorlar & Adet $x$ güç & Toplam güç \\
\hline Elektrik sarfiyatı & $1,3 \mathrm{kw} / \mathrm{m}^{3}$ & & $(\mathrm{HP})$ & $(\mathrm{HP})$ \\
\hline Toplam ağırlık (ton) & 3500 & Kaldırma & $4 \times 1045$ & 4180 \\
\hline Bom ağırlığı (ton) & 200 & Çekme & $4 \times 1045$ & 4180 \\
\hline Kepçe boş ağırlığı (ton) & 35 & Dönüş & $4 \times 640$ & 2560 \\
\hline Maksimum yük (ton) & 140 & Yürüyüş & $2 \times 800$ & 1600 \\
\hline Çalışma gerilimi volt) & 6300 & & & \\
\hline
\end{tabular}

\section{ARAZI ÇALIŞMALARI}

Arazi çalışmaları kapsamında farklı kayaç dayanımına sahip üç farklı ve herhangi bir süreksizlik özelliği içermeyen bölgelerde öncelikle çekme kepçeli yerkazarın direkt olarak kazı yapılması sağlanmıştır. Kazı sırasında tükettiği enerji miktarları kaydedilerek birim kazı maliyetleri belirlenmiştir. Daha sonra yine her deney bölgesi için aynı patlatma verileri kullanılarak patlayıcı madde ve patlatma delik delme maliyetleri belirlenmiştir. En sonunda ise üç farklı çalışma alanında delme-patlatma işlemi uygulandıktan sonra çekme kepçeli yerkazarın o bölgelerde çalışması sağlanarak birim kazı maliyetleri hesaplanmıştır. 


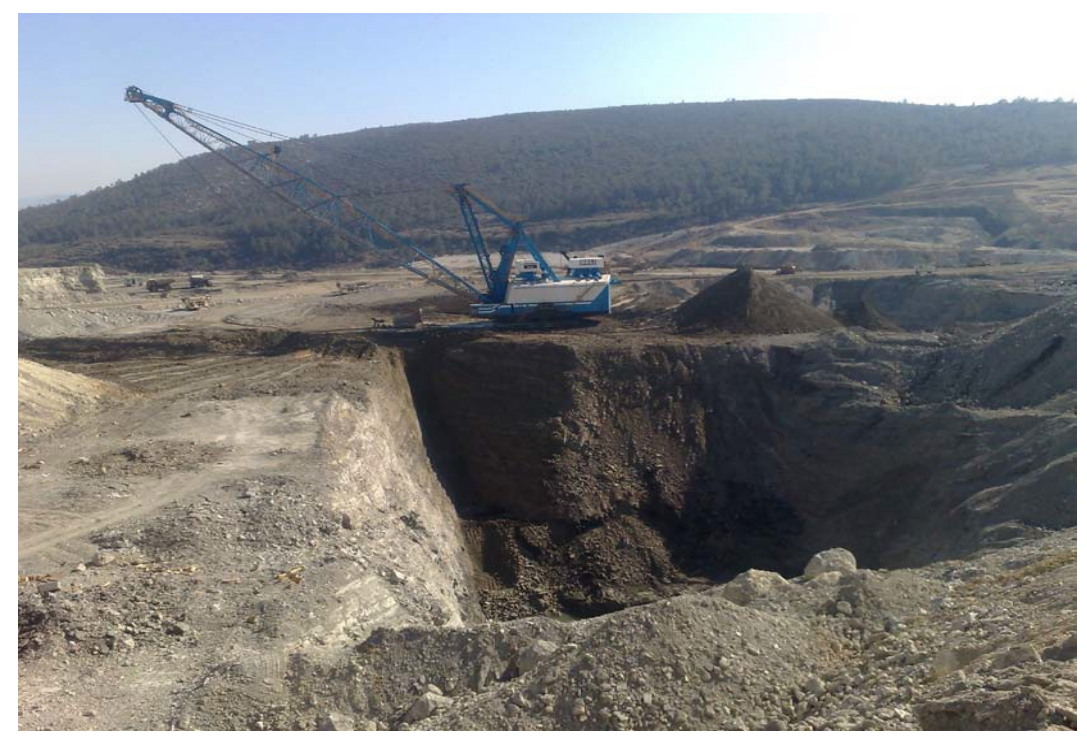

Şekil 2. Araştırmada kullanılan çekme kepçeli yerkazar görüntüsü.

Figure 2. The image of the dragline used in the research.

Çizelge 2. Çalışma bölgelerine ait laboratuvar deney sonuçları.

Table 2. Laboratory test results of studying areas.

\begin{tabular}{ccccc}
\hline $\begin{array}{c}\text { Deney } \\
\text { bölgesi }\end{array}$ & $\begin{array}{c}\text { Ortalama } \\
\text { birim } \\
\text { hacim } \\
\text { ağırlık } \\
\left(\mathrm{gr} / \mathrm{cm}^{3}\right)\end{array}$ & $\begin{array}{c}\text { Deney } \\
\text { sayısı }\end{array}$ & $\begin{array}{c}\text { Ortalama tek } \\
\text { eksenli basınç } \\
\text { dayanımı (MPa) }\end{array}$ & $\begin{array}{c}\text { Deney } \\
\text { sayısı }\end{array}$ \\
\hline 1. bölge & $1,54 \pm 0,003$ & 20 & $4,70 \pm 0,3$ & 19 \\
2. bölge & $1,58 \pm 0,004$ & 21 & $6,81 \pm 0,4$ & 10 \\
3. bölge & $1,72 \pm 0,005$ & 27 & $9,80 \pm 0,3$ & 25 \\
\hline
\end{tabular}

\section{Çekme kepçeli yerkazarın direkt kazı işlemleri ve maliyetleri}

Çekme kepçeli yerkazarların motorları elektrik tahrikli olduğundan dolayı bu kazıcıların ihtiyaç duyduğu elektrik enerjisi bir kesici yardımıyla trafodan alınmaktadır. Elektrik kesicisinin görevi, trafodan aldığı yüksek elektrik enerjisini düşürerek bir elektrik panosuna iletmektir (Şekil 3). 


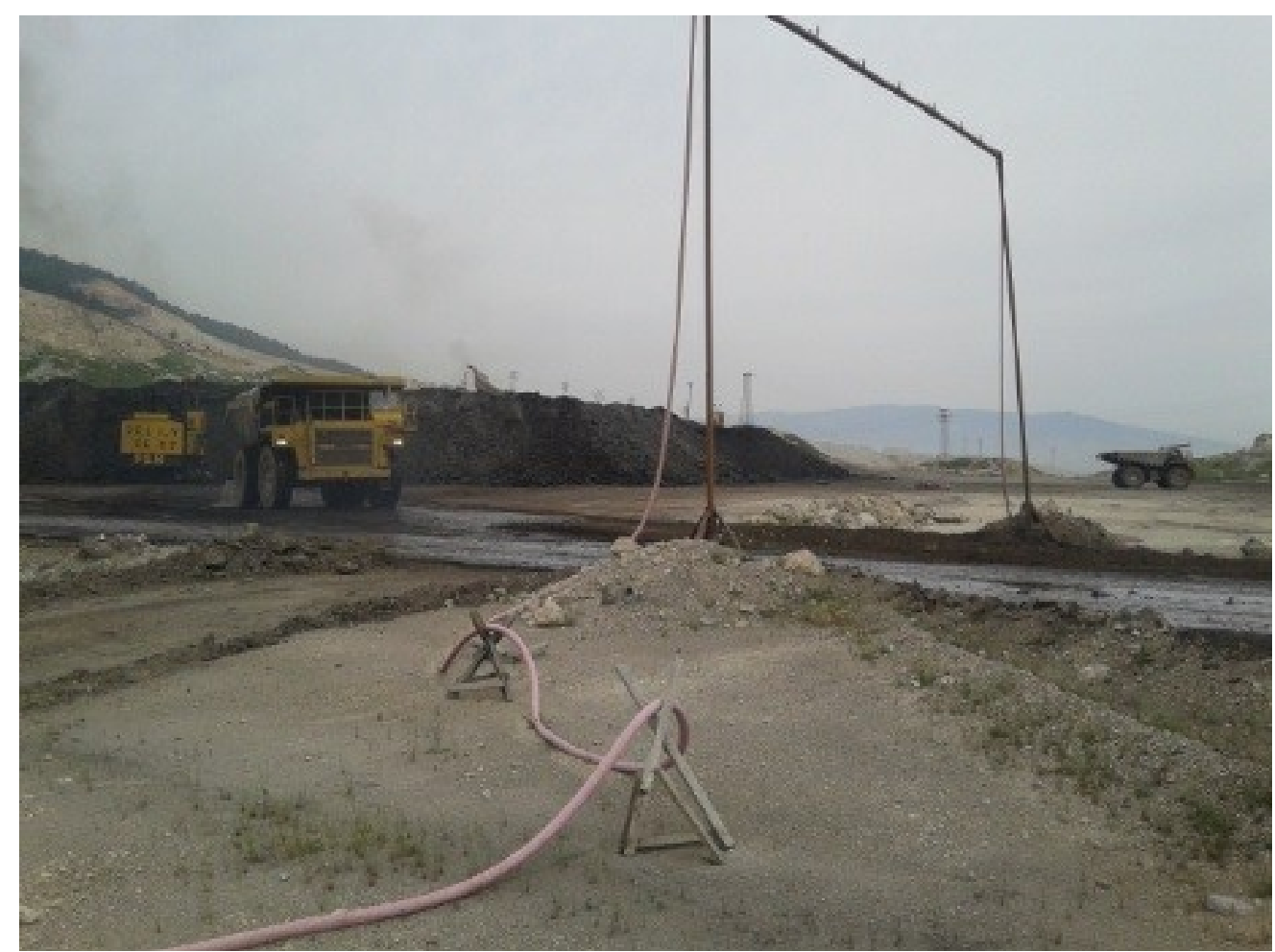

Şekil 3. Elektrik kesicisinin görünümü.

Figure 3. View of the electric breaker.

Çekme kepçeli yerkazarın kazı sırasında harcadığı amper değerleri, elektrik panosu üzerinde bulunan bir sayaçta anlık olarak görülebilmektedir (Şekil 4). Bu amper değerleri, çekme kepçeli yerkazarın kazı yaptığı bölgeler için kamera yardımıyla kayıt altına alınıp, daha sonra da bilgisayar ortamına aktarılarak ortalama olarak hesaplanmıştır. Sistemin volt değeri ise sürekli sabit olarak ortalama 6300 volt değerinde olmuştur.

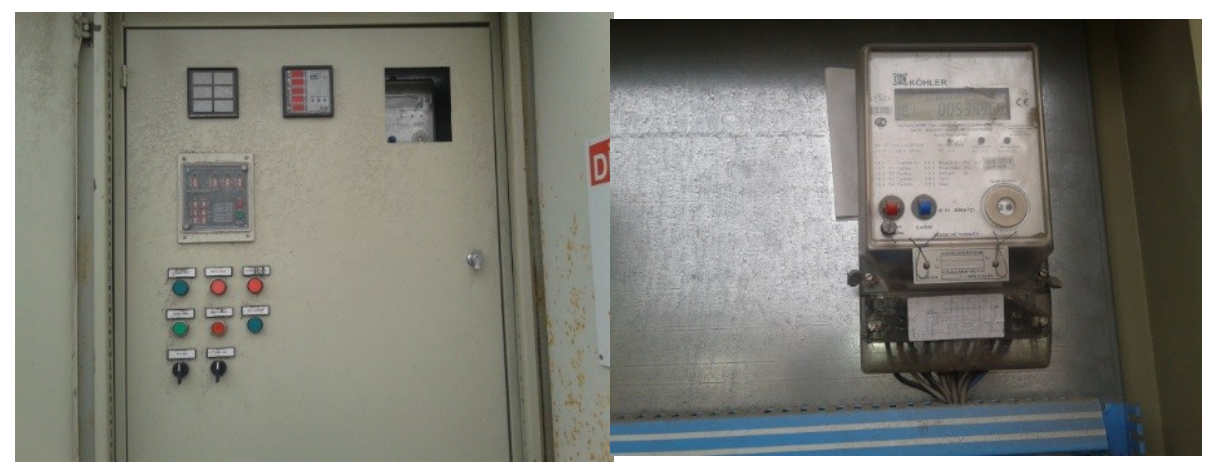

Şekil 4. Elektrik panosu ve elektrik sayacı.

Figure 4. Electrical panel and electricity meter. 
Çekme kepçeli yerkazarın kazı sırasında tükettiği amper değerleri, her bir deney bölgesi için ortalama olarak alınıp, aşağıda verilen bağıntı 1 yardımıyla çekme kepçeli yerkazarın kazı sırasında tükettiği ortalama güç değerleri hesaplanmıştır. Ayrıca çekme kepçeli yerkazarın kazı sıralarında ortalama çalışma saatleri ve toplam kazılan malzeme miktarları da deneyler yapılırken kaydedilmiştir. Çalışma saatleri gözlemlerle elde edilirken; ortalama toplam kazılan malzeme miktarları da çekme kepçeli yerkazarın kazı sırasında kullandığı kepçe sayısı ve kepçe hacmi değerleri kullanılarak kaydedilmiştir. Ortalama tüketilen güç değerleri ile çalışma saatleri çarpılmış ve elde edilen değerler, ortalama toplam kazılan malzeme miktarlarına bölünerek her bir deney bölgesi için birim kazı maliyetleri hesaplanmıştır. Birim maliyetlerin hesaplanmasında 1 kwh değeri 0,55 TL olarak alınmıştır (Çizelge 3).

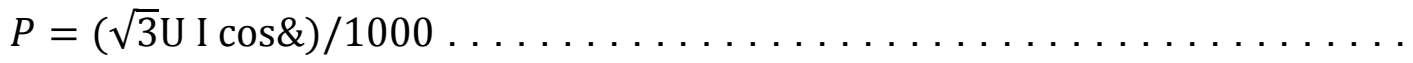

$\mathrm{P}=$ Kazı sırasında harcanan ortalama güç $(\mathrm{kw})$

$\mathrm{U}=$ Ortalama volt değeri $(6300 \mathrm{~V})$

I= Ortalama amper değeri $(A)$

$\cos \&=0,8$

Çizelge 3. Kazı sıralarında çekme kepçeli yerkazara ait ölçülen ve hesaplanan veriler

Table 3.Measured and calculated data of the dragline during excavation

\begin{tabular}{cccccccc}
\hline $\begin{array}{c}\text { Deney } \\
\text { bölgesi }\end{array}$ & $\begin{array}{c}\text { Ortalama } \\
\text { volt }(\mathrm{V})\end{array}$ & $\begin{array}{c}\text { Ortalama } \\
\text { amper } \\
(\mathrm{A})\end{array}$ & $\begin{array}{c}\text { Ortalama } \\
\text { tüketilen } \\
\text { güç }(\mathrm{kw})\end{array}$ & $\begin{array}{c}\text { Ortalama } \\
\text { çalışma } \\
\text { saati }\end{array}$ & $\begin{array}{c}\text { Ortalama } \\
\text { toplam } \\
\text { kazılan } \\
\text { malzeme } \\
\left(\mathrm{m}^{3}\right)\end{array}$ & $\begin{array}{c}\text { Tüketilen } \\
\text { birim enerji } \\
\left(\mathrm{kwh} / \mathrm{m}^{3}\right)\end{array}$ & $\begin{array}{c}\text { Birim } \\
\text { kazı } \\
\text { maliyeti } \\
\left(\mathrm{TL} / \mathrm{m}^{3}\right)\end{array}$ \\
\hline $\begin{array}{c}\text { Birinci bölge } \\
\text { İkinci bölge }\end{array}$ & 6300 & 153,2 & 1.337 & 24 & 24000 & 1,337 & 0,736 \\
$\begin{array}{c}\text { Üçüncü } \\
\text { bölge }\end{array}$ & 6300 & 181,5 & 1.584 & 25,8 & 24000 & 1,703 & 0,937 \\
\hline
\end{tabular}

1 kwh 0,55 TL olarak alınmıştır. 


\section{Patlayıcı madde maliyetinin belirlenmesi}

Her üç deney bölgesi için şeş-beş delik düzeni kullanılarak patlatma ile gevşetme işlemi yapılmıştır. Yine her üç deney bölgesinde üç sıralı ve her bir sırada beş patlatma deliği olmak üzere toplam 15 adet patlatma deliği delinmiştir. Delikler arası mesafe $10 \mathrm{~m}$, dilim kalınlığı 8 $\mathrm{m}$ ve delik boyları da $20 \mathrm{~m}$ olarak oluşturulmuştur. Patlatma delik geometrileri, çekme kepçeli yerkazarın direkt olarak kazısı sırasında kazdığı malzeme miktarı olan $24.000 \mathrm{~m}^{3}$ değerini verecek şekilde dizayn edilmiştir. Deneylerde kayacın parçalanmasında ANFO, yemleme olarak da dinamit tipi patlayıcı madde kullanılmıştır. Patlatma sonucu patlayan toplam malzeme miktarları her bir patlatma deneyi için patlatma delik geometrisi kullanılarak hesaplanmıştır. Bu verilerle, özgül şarj değerini ifade eden bir metre küp malzemenin patlaması için kullanılan toplam ANFO ve dinamit miktarları hesaplanmıştır. $1 \mathrm{~kg}$. patlayıcı madde fiyatı olan 6 TL ile özgül şarj değeri çarpılarak her üç deney bölgesi için de aynı olan birim patlayıcı madde maliyeti hesaplanmıştır. Şekil 5'de her üç deney bölgesi için kullanılan patlatma delik geometrisi sunulurken; Çizelge 4'de de ölçülen ve hesaplanan değerler verilmiştir.

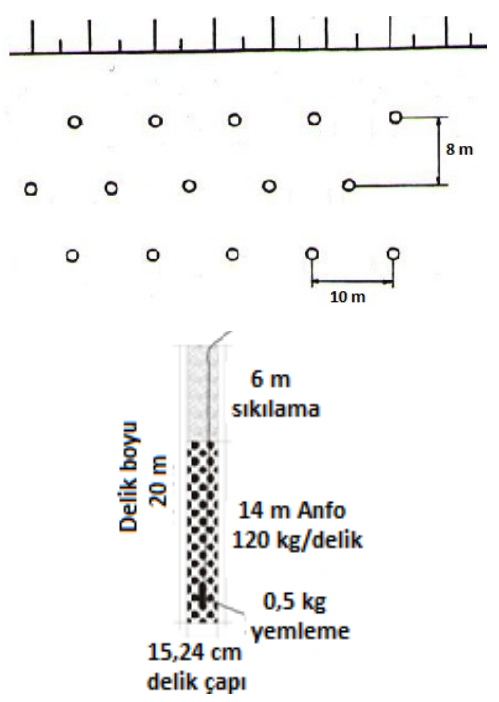

Şekil 5. Deney bölgelerinde kullanılan patlatma delik geometrisi.

Figure 5. Blast hole geometry used in test areas. 
Çizelge 4. Deney bölgelerinde kullanılan patlatma verileri.

Table 4. Blasting data used in test sites.

\begin{tabular}{ll}
\hline Delik Sayısı (adet) & 15 \\
Delik Çapı (cm) & 15,24 \\
Delik Boyu (m) & 20 \\
Delikler Arası Mesafe (m) & 10 \\
Dilim Kalınlı̆̆ı (m) & 8 \\
Sıkılama Boyu (m) & 6 \\
Şarj Kolonu Yüksekliği (m) & 14 \\
Yemleme (kg/delik) & 0.5 \\
Patlayıcı Madde Miktarı (ANFO) (kg/delik) & 120 \\
Toplam Patlayıcı Madde Miktarı (kg) & 1807,5 \\
Patlayan Toplam Malzeme (m ${ }^{3}$ ) & 24.000 \\
Özgül şarj (kg/m ${ }^{3}$ ) & 0,075 \\
Birim Patlayıcı Madde Maliyeti (TL/ m ${ }^{3}$ ) & 0,45
\end{tabular}

1 kg. ANFO 6 TL. olarak alınmıştır.

\section{Patlatma delik delme maliyetlerinin belirlenmesi}

Patlatma deneylerinde öncelikle patlayan toplam malzeme miktarları değerlerinin, delici çalışma saatleri değerlerine bölünmesiyle delici makinanın birim saatteki çalışma kapasiteleri belirlenmiş daha sonra da delici makinanın bir saatteki yakıt tüketim değerlerinin çalışma kapasitesi değerlerine bölünmesiyle de her bir patlatma deneyine ait bir metre küpteki yakıt tüketim değerleri bulunmuştur. 1 litre motorin fiyatı 6 TL olarak alınmış ve her bir çalışma bölgesi için birim delik delme maliyetleri tespit edilmiştir (Çizelge 5). Patlayan toplam malzeme miktarları patlatma delik geometrisine göre hesaplanırken; delici çalışma saatleri de ölçüm ve gözlemlerle belirlenmiştir. Ayrıca delici makinanın bir saatte tükettiği yakıt miktarı değerleri ortalama olarak delici kabininde bulunan monitör bilgisayarından elde edilmiştir. 
Çizelge 5. Delik delme maliyetleri.

Table 5. Drilling costs.

\begin{tabular}{lcccccccc}
\hline $\begin{array}{c}\text { Deney } \\
\text { bölgesi }\end{array}$ & $\begin{array}{c}\text { Delinen } \\
\text { delik } \\
\text { sayısı }\end{array}$ & $\begin{array}{c}\text { Delinen } \\
\text { toplam } \\
\text { delik } \\
\text { boyu } \\
(\mathrm{m})\end{array}$ & $\begin{array}{c}\text { Toplam } \\
\text { patlayan } \\
\text { malzeme } \\
\text { miktarı }\left(\mathrm{m}^{3}\right)\end{array}$ & $\begin{array}{c}\text { Delici } \\
\text { çalışma } \\
\text { saati }\end{array}$ & $\begin{array}{c}\text { Delici } \\
\text { çalışma } \\
\text { kapasitesi } \\
(\mathrm{m} 3 / \mathrm{saat})\end{array}$ & $\begin{array}{c}\text { Delici yakıt } \\
\text { tüketimi } \\
\text { (It./saat) }\end{array}$ & $\begin{array}{c}\text { Delici birim } \\
\text { yakıt } \\
\text { tüketimi (It./ } \\
\left.\mathrm{m}^{3}\right)\end{array}$ & $\begin{array}{c}\text { Birim delik } \\
\text { delme } \\
\text { maliyeti (TL/ } \\
\left.\mathrm{m}^{3}\right)\end{array}$ \\
\hline $\begin{array}{l}\text { Birinci } \\
\text { bölge }\end{array}$ & 15 & 300 & 24000 & 21,5 & 1116,279 & 27,63 & 0,025 & 0,149 \\
$\begin{array}{l}\text { Ikinci } \\
\text { bölge }\end{array}$ & 15 & 300 & 24000 & 24,8 & 967,742 & 30,21 & 0,031 & 0,187 \\
$\begin{array}{l}\text { Üçüncü } \\
\text { bölge }\end{array}$ & 15 & 300 & 24000 & 30,5 & 786,885 & 38,13 & 0,048 & 0,291 \\
\hline
\end{tabular}

1 It. motorin 6 TL olarak alınmıştır.

\section{Gevşetme işlemi sonrası çekme kepçeli yerkazara ait kazı işlemleri ve maliyetleri}

Aynı deney bölgelerinde delme-patlatma yöntemiyle gevşetme işlemi yapıldıktan sonra yine aynı çekme kepçeli yerkazar ile kazı operayonları gerçekleştirilmiştir. Çekme kepçeli yerkazarın direkt kazı sırasında elde edilen maliyet yöntemi uygulanarak gevşetme işlemi sonrası çekme kepçeli yerkazarın kazı maliyetleri hesaplanmıştır (Çizelge 6).

Çizelge 6. Gevşetme işleminden sonra çekme kepçeli yerkazara ait ölçülen ve hesaplanan veriler.

Table 6. Measured and calculated data of the dragline after loosening operation.

\begin{tabular}{cccccccc}
\hline $\begin{array}{c}\text { Deney } \\
\text { bölgesi }\end{array}$ & $\begin{array}{c}\text { Ortalama } \\
\text { volt }(\mathrm{V})\end{array}$ & $\begin{array}{c}\text { Ortalama } \\
\text { amper } \\
(\mathrm{A})\end{array}$ & $\begin{array}{c}\text { Ortalama } \\
\text { tüketilen } \\
\text { güç }(\mathrm{kw})\end{array}$ & $\begin{array}{c}\text { Ortalama } \\
\text { çalışma } \\
\text { saati }\end{array}$ & $\begin{array}{c}\text { Ortalama } \\
\text { toplam } \\
\text { kazılan } \\
\text { malzeme } \\
\left(\mathrm{m}^{3}\right)\end{array}$ & $\begin{array}{c}\text { Tüketilen } \\
\text { birim enerji } \\
\left(\mathrm{kwh} / \mathrm{m}^{3}\right)\end{array}$ & $\begin{array}{c}\text { Birim } \\
\text { kazı } \\
\text { maliyeti } \\
\left(\mathrm{TL}^{3} \mathrm{~m}^{3}\right)\end{array}$ \\
\hline $\begin{array}{c}\text { Birinci } \\
\text { bölge } \\
\text { İkinci } \\
\text { bölge }\end{array}$ & 6300 & 133,2 & 1162,740 & 19 & 24000 & 0,921 & 0,506 \\
$\begin{array}{c}\text { Üçüncü } \\
\text { bölge }\end{array}$ & 6300 & 141,5 & 1235,193 & 20,8 & 24000 & 1,071 & 0,589 \\
\hline
\end{tabular}

1 kwh 0,55 TL olarak alınmıştır. 


\section{TARTIŞMA}

Çizelge 7'de çekme kepçeli yerkazara ait direkt birim kazı, birim patlayıcı madde, birim delik delme ve gevşetme işlemi sonrası çekme kepçeli yerkazara ait birim kazı maliyetleri görülmektedir. Çizelge 7'de ayrıca tüm deney bölgeleri için birim patlayıcı madde, birim delik delme ve gevşetme işlemi sonrası çekme kepçeli yerkazara ait birim kazı maliyetleri toplanarak delme-patlatmaya ilaveten birim kazı maliyetleri de hesaplanmıştır. Birinci ve ikinci deney bölgesinde çekme kepçeli yerkazar ile direkt kazı daha avantajı olurken; üçüncü deney bölgesinde ise bu durum, delme-patlatmaya ilaveten birim kazıyı daha avantajı kılmaktadır. Diğer bir deyişle tek eksenli basınç dayanımı 9,80 MPa ve daha yukarısına sahip olan sahalarda, delme-patlatma işleminden sonra kazı yapılması daha ekonomik olacaktır. İkinci deney bölgesinin sahip olduğu kayaç dayanımı olan 6,81 MPa ile üçüncü deney bölgesine ait 9,80 MPa kayaç dayanımı değerleri arasında kalan sahalarda, direkt kazının mı yoksa gevşetme sonrası kazının mı daha avantajı olduğu belirli değildir. Bu durumun belirlenmesi için söz konusu kayaç dayanımı değerleri arasında kalan sahalarda deneylerin yapılması önemlidir. Deneyler herhangi bir süreksizlik özelliği içermeyen bölgelerde gerçekleştirilmiştir. Bu nedenle bu deneylerin süreksizlik özelliği içeren sahalarda da yapılması önemlidir.

Çizelge 7. Direkt kazı, delme-patlatma ve gevşetme sonrası birim kazı maliyetleri.

Table 7. Unit excavation costs of direct excavation, drilling and blasting and after loosening excavation.

\begin{tabular}{|c|c|c|c|c|c|}
\hline Deney bölgesi & $\begin{array}{c}\text { Çekme kepçeli } \\
\text { yerkazar direkt } \\
\text { birim kazı } \\
\text { maliyeti (TL/ } \\
\mathrm{m}^{3} \text { ) }\end{array}$ & $\begin{array}{l}\text { Birim Patlayıcı } \\
\text { Madde Maliyeti } \\
\left(\mathrm{TL} / \mathrm{m}^{3}\right)\end{array}$ & $\begin{array}{l}\text { Birim delik } \\
\text { delme maliyeti } \\
\left(\mathrm{TL} / \mathrm{m}^{3}\right)\end{array}$ & $\begin{array}{c}\text { Gevşetme } \\
\text { işlemi sonrası } \\
\text { Çekme kepçeli } \\
\text { yerkazar birim } \\
\text { kazı maliyeti } \\
\left(\mathrm{TL} / \mathrm{m}^{3}\right)\end{array}$ & $\begin{array}{c}\text { Delme- } \\
\text { patlatmaya } \\
\text { ilaveten birim } \\
\text { kazı maliyeti } \\
\left(\mathrm{TL} / \mathrm{m}^{3}\right)\end{array}$ \\
\hline Birinci bölge & 0,736 & \multirow{3}{*}{0,45} & 0,149 & 0,506 & 1,105 \\
\hline İkinci bölge & 0,937 & & 0,187 & 0,589 & 1,226 \\
\hline Üçüncü bölge & 1,629 & & 0,291 & 0,644 & 1,385 \\
\hline
\end{tabular}

\section{SONUÇLAR}

Tek eksenli basınç dayanımı 4,70, 6,81 ve 9,80 MPa olan birbirinden farklı kayaç dayanımına sahip ve herhangi bir süreksizlik özelliği içermeyen üç farklı sahada $50 \mathrm{~m}^{3}$ kepçe kapasitesine sahip çekme kepçeli yerkazar ile öncelikle direkt olarak kazı deneyleri yapılmış ve bu 
deneylere ait birim kazı maliyetleri belirlenmiştir. Bu değerler, birinci sahada 0,736, ikinci sahada 0,937 ve üçüncü sahada da $1,629 \mathrm{TL} / \mathrm{m}^{3}$ olarak bulunmuştur. Daha sonra yine aynı sahalarda aynı delme-patlatma verileri kullanılarak delme-patlatma işlemi gerçekleştirilmiş ve bunlara ait birim patlayıcı madde ve birim delik delme maliyetleri tespit edilmiştir. Birim patlayıcı madde maliyeti her üç saha için de $0,45 \mathrm{TL} / \mathrm{m}^{3}$ olarak hesaplanırken; birim delik delme maliyetleri de sırasıyla $0,149,0187$ ve $0,291 \mathrm{TL} / \mathrm{m}^{3}$ olarak ortaya çıkmıştır. Delmepatlatma işlemleri ile gevşetme sonrası tekrar aynı çekme kepçeli yerkazar ile söz konusu üç sahada da kazı operasyonları tekrarlanarak çekme kepçeli yerkazara ait birim kazı maliyetleri hesaplanmıştır. Bunlar yine sırasıyla 0,506, 0,589 ve 0,644 TL/m ${ }^{3}$ değerleridir. En sonunda tüm çalışma sahaları için birim patlayıcı madde, birim delik delme ve gevşetme işlemi sonrası çekme kepçeli yerkazara ait birim kazı maliyetleri toplanarak delme-patlatmaya ilaveten birim kazı maliyetleri ortaya çıkarılmıştır. Bunlar birinci sahada 1,105, ikinci sahada 1,226 ve üçüncü sahada da $1,385 \mathrm{TL} / \mathrm{m}^{3}$ olarak bulunmuştur. Yapılan değerlendirmeler sonucunda kayaç dayanımı 9,80 MPa ve daha yukarısına sahip olan sahalarda, delme-patlatma işleminden sonra kazı yapılmasının daha ekonomik olduğu tespit edilmiştir.

\section{KAYNAKLAR}

Abdüllatif, O.M., Cruden, D.M., 1983. The relationship between rock mass quality and ease of excavation. Bulletin of the International Association of Engineering Geology, 28, 183187.

Bieniawski, Z.T., 1973. Engineering classification of jointed rock masses. The Civil Engineer in South Africa, 15, 335-343.

Franklin, J.A., Broch, E., Walton, G., 1971. Logging the mechanical character of rock. Transactions of the Institution of Mining and Metallurgy, 80, A1-A9.

Göktan, R.M., Eskikaya, Ş., 1991. Prediction of ripping machine performance in terms of rock mass properties. The Civil Engineer in South Africa, 31, 13-24.

Karpuz, C., 1990. A classification system for excavation of surface coal measures. Mining Science and Technology, 11, 157-163. 
Kirsten, H.A.D., 1982. A classification system for excavation in natural materials. Die Siviele Ingenieur in Suid-Afrika, 82, 293-307.

Müftüoğlu, Y.V., Scoble, M.J., 1985. Kömür açık işletmeciliğinde kazılabilirliği belirleme yöntemleri. Türkiye Madencilik Bilimsel ve Teknik 9. Kongresi, Ankara. 29-37.

Pettifer, G.S., Fookes, P.G., 1994. A revision of the graphical method for assessing the excavatability of rock, Quarterly Journal of Engineering Geology. 27, 145-164.

Singh, R.N., Denby, B., Egretli, I., Pathan, A.G., 1986. Assessment of ground rippability in opencast mining operations. Mining Magazine, University of Nottingham, 38, 21-34.

Weaver, J.M., 1975. Geological factors significant in the assessment of rippability. Die Siviele Ingenieur in Suid-Afrika, 17, 313-316. 